\title{
The Influence of Sense of Community on Nursing Students: A Cross-Sectional Study on their Satisfaction in a Distance Learning Environment
}

Adnan Innab ( $\square$ ainnab@ksu.edu.sa )

King Saud University

Monirah Albloushi

King Saud University

Mohammed Alruwaili

King Saud University

Latifah Alenazi

King Saud University

Alwah Alkathiri

King Saud University

\section{Research Article}

Keywords: Satisfaction, nursing, students, distance learning, Sense of community, Saudi Arabia

Posted Date: September 29th, 2021

DOI: https://doi.org/10.21203/rs.3.rs-937167/v1

License: (c) (1) This work is licensed under a Creative Commons Attribution 4.0 International License. Read Full License 


\section{Abstract}

Background: The COVID-19 pandemic has caused a sudden shift to distance learning. For many nursing students, distance learning was a new experience. Along with being an essential requirement for retaining students, developing a sense of community is a factor influencing students' success in distance learning. Assessments of the effectiveness of e-learning have been well documented in the literature. However, there is a dearth of research that assessed nursing students' sense of community. This study aimed to assess students' sense of community during e-learning, while determining its impact on their level of satisfaction.

Methods: This cross-sectional descriptive study used convenience sampling to collect data via a student satisfaction survey and a classroom community scale. Nursing students were recruited from 13 public and private nursing programs in Saudi Arabia.

Results: There was a positive and significant correlation between a sense of community and satisfaction with teaching $(r=.269, p<.001)$, satisfaction with assessment $(r=.258, p<.001)$, satisfaction with generic skills and learning experiences $(r=.238, p<.001)$, and total satisfaction with e-learning $(r=.07, p$ $<.001)$. Students who perceived themselves as working collaboratively with their classmates and being more engaged in their learning were more satisfied with e-learning $(p<.01)$. There were no significant variations in the participants' satisfaction by age $(\beta=-.06, p>.05)$ and $\operatorname{sex}(\beta=-.283, p>.05)$. However, school level was significantly correlated with satisfaction with e-learning. Specifically, students in lower levels of their nursing school had higher satisfaction rates with e-learning $(95 \% \mathrm{Cl}[.08,1.33]$, $[\mathrm{F}(3,99)=$ $\left.\left.6.96, p<.001, \beta=-.335, R^{2}=.174\right]\right)$.

Conclusions: Failing to meet student expectations can lead to low levels of student involvement. Thus, students' engagement and satisfaction are good indicators of the quality and effectiveness of online programs. This study calls for further action through seminars and training sessions to introduce innovative teaching techniques and alternative assessment plans for learners in advanced levels. This study helps educational institutions devise strategies to enhance the level of interaction and cooperation among nursing students.

\section{Background}

In most institutions, distance learning is not a novel strategy of instruction. Murphy ${ }^{1}$ stated that the spread of the coronavirus disease 2019 (COVID-19) affected education systems globally; moreover, health professionals' education and training were negatively affected by the lockdown due to the ongoing pandemic. At the beginning of the pandemic, all courses switched to the online medium to reduce transmission of the causative virus and enhance social distancing between students. To achieve learning outcomes and sustain the learning process, several programs shifted all their classes to distance learning using varied online educational platforms. Taylor et $\mathrm{al}^{2}$ reported that distance learning was an effective strategy for delivering course content. 
The use of e-learning in higher education has grown rapidly in the last decade. ${ }^{3}$ E-learning is a valuable learning method, as it allows students flexibility in their learning experiences and enables them to study at a time and location that is convenient for them. According to several studies, students consider distant learning to not only be simple to use, ${ }^{4}$ but also comfortable and accessible due to readily available learning materials. ${ }^{5}$

Similar to other programs across the globe, the nursing programs in Saudi Arabia (SA) moved to a distance-learning mode due to the rise in COVID-19 cases to help students complete the required courses. The sudden shift to distance learning was a new experience for many nursing students. ${ }^{6}$ Assessments of the effectiveness of e-learning have been well documented in the literature. However, there is a dearth of research that assessed nursing students' sense of community and its impact on their satisfaction.

Along with being an essential requirement for retaining students, developing a sense of community is a factor influencing students' success in distance learning. ${ }^{7}$ The concept of a classroom community refers to the sense that members matter to one another and to the group, that they have responsibilities and obligations to one another and to the school, and that they have shared expectations, through which members' educational needs will be satisfied through shared learning goals. ${ }^{8}$

Connectedness and learning are two components of the sense of a classroom community in online classes. Rovai ${ }^{8}$ identified the following four essential prerequisites to support the development of a sense of community in an online class: spirit (recognition of membership), trust (willingness to rely on other team members), interaction (either task-driven or socio-emotional in origin), and the commonality of expectations and goals (learning). A sense of community in online classes is essential to promote students' satisfaction and help them feel connected and engaged. Instructors and faculty members are responsible for building students' sense of community in online classes by designing interactive learning experiences. ${ }^{9}$ Collaborative activities, ${ }^{10}$ discussions, ${ }^{11,12}$ sharing resources and personal experiences, and creating opportunities for introductions ${ }^{13}$ are e-learning strategies. Online discussions facilitate student interaction and provide them with opportunities to discuss academic and personal experiences with their peers. ${ }^{13}$

Learning occurs when students participate, engage, and collaborate with each other. ${ }^{11,12}$ The instructors enhance students' sense of community through regular communication, quality feedback, support, and interactions with the students. ${ }^{11,14}$ Furthermore, synchronous activities allow students to learn and interact with their peers and instructors. ${ }^{15}$ Different methods have been identified to enhance students' sense of community in online classes, such as social networking platforms, ${ }^{15}$ video conferencing, ${ }^{16}$ asynchronous discussion boards, ${ }^{12}$ and collaborative tools such as Google Workspace (Google LLC, Mountain View, CA, USA). ${ }^{17}$

Prior studies report a positive association between a sense of community in online classes and student satisfaction . ${ }^{13,18}$ Perceived learning, satisfaction, engagement, and achievements were also positively 
influenced by the sense of community in online classes. ${ }^{8,19}$ LaBarbera $^{14}$ reported that students' satisfaction with online classes was greater among those who felt engaged and got along with classmates and instructors. However, studies comparing students' sense of community between online and face-to-face classes found that they experienced a higher level of satisfaction in the latter. ${ }^{20}$ The unexpected switch to online teaching may have affected students' sense of community and satisfaction with online classes, especially when instructors lacked the skills required to implement strategies to create a classroom community in this context. ${ }^{21,22}$

Student responses are vital guidelines of concern within online courses, as they reflect many variations regarding the sense of community, especially in distance learning. A sense of community can be achieved desirably in a well-structured manner to facilitate the satisfaction and comfort of online learners regarding knowledge acquisition. Therefore, this study aimed to assess students' sense of community during e-learning, while determining its impact on their level of satisfaction.

\section{Methods}

\section{Design and Sampling}

This was a cross-sectional, descriptive study. The study data were collected at a single point in time using the convenience sampling method. The inclusion criteria were: 1) current enrolment as an undergraduate nursing student, 2) prior or current enrollment in practical courses (e.g., health assessment course, adult, or critical care courses), 3) current enrolment in courses that were completely online, hybrid, or face-toface, and 4) were proficient in English, as the study questionnaires were not translated into the Arabic language. Internship students who were no longer taking theoretical and clinical courses were excluded.

G-power software 3.1 (Heinrich-Heine-Universität, Düsseldorf, Germany) was employed to determine the sample size. A minimum of 92 participants were required to run the bivariate Pearson's correlation and multiple linear regression tests. Our sample size was 103 participants.

\section{Setting and Data Collection}

Approval from the appropriate ethics committee (Institutional Review Board) was obtained prior to the study onset. Permission to use the instruments was obtained from the authors prior to data collection. As the education system was largely online across the entire country during the initial period of the COVID-19 pandemic, nursing students were recruited using social media, such as Twitter (Twitter, Inc., San

Francisco, CA, USA), student clubs, and university email accounts. Students were recruited from 13 public and private nursing programs in Saudi Arabia.

During the semester and prior to the final exams, students were presented with the recruitment statement, the Classroom Community Scale, and the Students' Satisfaction Scale. Anonymous surveys were created using an online platform. The recruitment statement included specific information regarding participants' privacy, confidentiality, risks, and benefits of participation. Students were informed that participation in 
this study was completely voluntary, and that there would not be any consequences if they decided to withdraw participation. Moreover, they were informed that no identifiers would be collected, and that all gathered data would be reported in aggregate form.

\section{Measurements}

The sociodemographic form requested information on age, sex, and the current semester in nursing school.

\section{Student Outcomes Survey}

This self-report instrument aimed to measure students' satisfaction with their learning. It included 19 items and three subscales (i.e., teaching, assessment, generic skills, and learning experiences). ${ }^{23}$ All items were rated on a 5-point Likert scale that ranged from 1 (strongly disagree) to 5 (strongly agree). Higher scores indicate a greater level of satisfaction. This instrument was previously deployed with the same population and demonstrated reliable and valid results. ${ }^{24}$ In this study, the Cronbach's alpha (a) values were .92 for teaching, .94 for assessment, and .95 for generic skills and learning experiences.

\section{Classroom Community Scale}

The Classroom Community Scale aimed to measure the sense of community in a particular learning environment. ${ }^{8}$ This self-reported measure comprised 20 items and two subscales: connectedness and learning. Each item was measured on a 5-point Likert scale, ranging from strongly agree to strongly disagree. Specific items within each subscale were reverse-coded in this study to ensure that the least favorable choice imparted a small value, and the most favorable choice was assigned a high value. This instrument has previously shown reliable and valid results. ${ }^{8}$ In this study, the Cronbach's a values were .75 for connectedness and .70 for learning, which were towards the lower end of acceptability.

\section{Data Analysis}

The Statistical Package for the Social Sciences (SPSS) software version 28 (IBM Corporation, Armonk, NY, USA) was used to analyze the results. Data management and cleanup were completed prior to the analysis. Descriptive statistics (mean $[M]$, standard deviation [SD], and percentage values) were used to describe the demographic characteristics and missing data across all the variables. Except for the demographic questions, all of the items were completed using the force completion option. None of the variables had missing data of greater than $5 \%$.

The reliability coefficient was calculated for the scales and subscales. Bivariate correlation and simple linear regression tests were used to determine the relationship between the sense of community and students' satisfaction. A multiple linear regression test was conducted to determine the relationship between nursing students' characteristics and their satisfaction with e-learning.

\section{Results}


Table 1 shows the demographic characteristics of the participants $(n=103)$. The students' ages ranged from 18-23 years, with the majority being from 18-20 years old (63.1\%). Female students comprised $84.5 \%$ of the study sample. Regarding the level of education, all students were currently enrolled in a bachelor's program of nursing (BSN), and most of the participants were in their second (59.2\%) or third $(35.9 \%)$ years.

Table 1

Sample Characteristics of the Participants $(N=103)$.

\begin{tabular}{|c|c|}
\hline Variable (Range) & $n(\%)$ \\
\hline \multicolumn{2}{|l|}{ Age (years) } \\
\hline $18-20$ & $65(63.1)$ \\
\hline $21-23$ & 38 (36.9) \\
\hline \multicolumn{2}{|l|}{ Sex } \\
\hline Male & $16(15.5)$ \\
\hline Female & $87(84.5)$ \\
\hline \multicolumn{2}{|l|}{ Level of Education } \\
\hline Level 3 & $4(3.9)$ \\
\hline Level 4 & $57(55.3)$ \\
\hline Level 5 & $28(27.2)$ \\
\hline Level 6 & $9(8.7)$ \\
\hline Level 7 & $5(4.9)$ \\
\hline \multicolumn{2}{|c|}{$\begin{array}{l}\text { Note. Levels } 3 \text { and } 4=\text { second year of schooling, levels } 5 \text { and } 6=\text { third year, and level } 7=\text { fourth year. } \\
\text { Table } 2 \text { shows the average score and reliability coefficient for students' sense of community and } \\
\text { satisfaction regarding e-learning. As indicated earlier, the possible scores of the scales and subscales } \\
\text { ranged from } 1 \text { (strongly disagree) to } 5 \text { (strongly agree). The average score of the sense of community } \\
\text { scale was moderate }(M=3.3 \text { points, } S D=.54) \text {. However, the total score of students' satisfaction was } \\
\text { almost high }(M=3.99 \text { points, } S D=.87) \text {, which reflected that the students were almost satisfied with } \\
\text { the e-learning. The overall reliability coefficient for the sense of community subscales ranged from } \\
\text {.70-.75, while the Cronbach's coefficient values for the satisfaction subscales ranged from } .92-.95, \\
\text { thus indicating reliability and suitability of this scale. }\end{array}$} \\
\hline
\end{tabular}


Table 2

The Average Scores and Reliability of the Scales.

\begin{tabular}{|lll|}
\hline Variable & $\boldsymbol{M ( \pm S D )}$ & Cronbach's a \\
\hline Sense of community scale & $3.3(.62)$ & \\
\hline Connectedness & $3.33(.69)$ & .75 \\
\hline Learning & $3.25(.62)$ & .70 \\
\hline Satisfaction scale & $3.99(.87)$ \\
\hline Teaching & $4.22(.83)$ & .94 \\
\hline Assessment & $3.86(.97)$ & .92 \\
\hline Generic skills and learning experiences & $3.89(1.0)$ & .95 \\
\hline
\end{tabular}

The bivariate correlation showed a positive and significant correlation between the sense of community and satisfaction with teaching $(r=.269, p<.001)$, assessment $(r=.258, p<.001)$, generic skills and learning experiences $(r=.238, p<.001)$, and total satisfaction with e-learning $(r=.07, p<.001)$. Next, a simple linear regression test was used to determine the strength of the relationship between the sense of community and students' satisfaction with e-learning, the results of which indicated a positive and significant relationship (95\% confidence interval (CI) $[.08,1.33]$, $\left[\mathrm{F}(1,101)=8.08, p<.01, \beta=.374, R^{2}\right.$ $=.07])$. Students who perceived themselves as working collaboratively with their classmates and being more engaged in their learning were more satisfied with e-learning (Table 3 ).

Table 3

Relationship between the Sense of Community and Satisfaction about E-learning and its Subscales ( $N=$ 103).

\begin{tabular}{|c|c|c|c|c|c|c|c|c|}
\hline \multirow[t]{2}{*}{ Variables } & \multicolumn{2}{|c|}{$\begin{array}{l}\text { Total } \\
\text { Satisfaction }\end{array}$} & \multicolumn{2}{|c|}{$\begin{array}{l}\text { Satisfaction with } \\
\text { Teaching Subscale }\end{array}$} & \multicolumn{2}{|c|}{$\begin{array}{l}\text { Satisfaction with } \\
\text { Assessment } \\
\text { Subscale }\end{array}$} & \multicolumn{2}{|c|}{$\begin{array}{l}\text { Satisfaction with } \\
\text { Generic Skills } \\
\text { Subscale }\end{array}$} \\
\hline & $\mathrm{B}^{\mathrm{a}}$ & $\beta^{b}$ & B & $\beta$ & B & $\beta$ & B & $\beta$ \\
\hline $\begin{array}{l}\text { Sense of } \\
\text { Community }\end{array}$ & .378 & .272 & .357 & .269 & .400 & .258 & .378 & .238 \\
\hline \multirow{2}{*}{$\begin{array}{l}\text { Model } \\
\text { Summary }\end{array}$} & \multicolumn{2}{|c|}{$\mathrm{R}^{2}=.07 * \star$} & \multicolumn{2}{|c|}{$\mathrm{R}^{2}=.07 \star \star$} & \multicolumn{2}{|c|}{$\mathrm{R}^{2}=.07 \star \star$} & \multicolumn{2}{|c|}{$\mathrm{R}^{2}=.06^{\star}$} \\
\hline & \multicolumn{2}{|c|}{$r^{\dagger}=.272^{\star *}$} & \multicolumn{2}{|c|}{$r^{\dagger}=.269 * *$} & \multicolumn{2}{|c|}{$\mathrm{r}^{\dagger}=.258^{\star *}$} & \multicolumn{2}{|c|}{$r^{\dagger}=.238^{*}$} \\
\hline
\end{tabular}

Multiple linear regression analyses were used to determine the relationship between the participants' demographic characteristics and their satisfaction with e-learning (Table 4). There were no significant variations in the participants' satisfaction by age $(\beta=-.06, p>.05)$ and $\operatorname{sex}(\beta=-.283, p>.05)$. However, the level of education was significantly correlated with satisfaction with e-learning. Specifically, students 
in lower levels of their nursing school had higher satisfaction rates $(95 \% \mathrm{Cl}[.08,1.33]$, [F $(3,99)=6.96, p$ $\left.\left.<.001, \beta=-.335, R^{2}=.174\right]\right)$.

Table 4

Relationship between Students' Demographic Characteristics and Satisfaction About E-learning and its Subscales $(N=103)$.

\begin{tabular}{|c|c|c|c|c|c|c|c|c|}
\hline \multirow[t]{2}{*}{ Variables } & \multicolumn{2}{|c|}{ Satisfaction } & \multicolumn{2}{|c|}{$\begin{array}{l}\text { Teaching } \\
\text { Subscale }\end{array}$} & \multicolumn{2}{|c|}{$\begin{array}{l}\text { Assessment } \\
\text { Subscale }\end{array}$} & \multicolumn{2}{|c|}{$\begin{array}{l}\text { Generic Skills } \\
\text { Subscale }\end{array}$} \\
\hline & $\mathrm{B}^{\mathrm{a}}$ & $\beta^{\mathrm{b}}$ & B & $\beta$ & B & $\beta$ & B & $\beta$ \\
\hline Age & -.065 & -.036 & .078 & .045 & .101 & -.05 & -.172 & -.083 \\
\hline Sex (male) & -.283 & -.118 & -.195 & -.085 & -.282 & -.105 & -.372 & -.136 \\
\hline $\begin{array}{l}\text { Semester in Nursing } \\
\text { School }\end{array}$ & -.335 & -.342 & -.379 & -.406 & -.304 & -.278 & -.321 & -.288 \\
\hline Model Summary & \multicolumn{2}{|c|}{$\mathrm{R}^{2}=.174^{\star \star \star}$} & \multicolumn{2}{|c|}{$\mathrm{R}^{2}=.193^{\star \star \star}$} & \multicolumn{2}{|c|}{$\mathrm{R}^{2}=.125^{\star \star}$} & \multicolumn{2}{|c|}{$\mathrm{R}^{2}=.318^{\star \star *}$} \\
\hline
\end{tabular}

\section{Discussion}

Online education has emerged as an essential part of the Saudi Arabian education system. In particular, it has established its significance by enabling students to continue their learning during the COVID-19 pandemic. However, evaluating the effectiveness of online education in SA is challenging due to the differences in students' schooling levels, specialty types, and age groups. Recent studies have reported controversial results regarding the effectiveness of online learning in SA. For instance, Mahyoob ${ }^{25}$ conducted a study on 333 students from three public universities and emphasized the positive effect of online learning on students' achievement. However, based on students' perspectives, Aboud ${ }^{26}$ reported $^{\prime}$ that e-learning was ineffective and limited students' interactions with their classmates.

In our study, we found that nursing students were almost satisfied with e-learning. A number of researchers collected data from various nursing programs in SA and revealed that nursing students were somewhat satisfied with e-learning. ${ }^{24}$ In contrast, Abbasi et al ${ }^{27}$ collected data from 1,255 nursing students from 11 countries, and revealed that $34 \%$ of the students were not confident about completing the exit exam after participating in e-learning. However, differences in the overall satisfaction of nursing students could be attributed to varied implementations of e-learning in these countries.

We also found a significant and positive relationship between the sense of community (connectedness and learning) and satisfaction with e-learning. This result was consistent with those of previous studies. Rajabalee and Santally ${ }^{28}$ collected data from students in different disciplines and found a significant relationship between learners' engagement and satisfaction with the learning-teaching process. Moreover, the level of satisfaction was also directly associated with students' performance. ${ }^{28}$ Several researchers 
designed a framework to reveal the factors (e.g., anxiety, course quality, self-efficacy, interactions with others, instructor presence, and guidance) influencing learners' satisfaction with e-learning. In one study,

perceived interactions with other students had the largest effect (30\%) on student satisfaction. ${ }^{29}$ However, there are few studies focusing on the sense of community and satisfaction with e-learning among nursing students, which prevents us from drawing comparisons across the same discipline.

Moreover, we found that students in lower levels of nursing school had higher satisfaction rates compared to those in advanced levels. Nursing students in lower levels learn nursing skills, prior to the onset of clinical practice, ${ }^{30}$ which can be more feasible through e-learning. Those at advanced levels, such as in their internship year, must apply the learned nursing skills in clinical settings. ${ }^{31}$ Similar findings were reported by Abbasi et $\mathrm{al}^{27}$ who found that more than two-thirds of the nursing students believed that practical skills were best learned in clinical settings. Thus, the evaluation of clinical competence among nursing students in their internship year who specifically participated in e-learning warrants further investigation.

\section{Implications}

Education serves as a basic pillar of the development of a country. Owing to the COVID-19 pandemic, the online learning medium is predominantly used in education systems. ${ }^{24}$ In this context, our study is relevant as it holds implications for the future of teaching and learning in technology-enabled learning environments. Online learning, being novel, has not only disrupted traditional teaching practices, but also teachers have experienced difficulties in adapting to this medium. Failing to meet student expectations can lead to low levels of student involvement. Thus, students' satisfaction and engagement are good indicators of the quality and effectiveness of online programs. Nursing programs must recognize if their students are satisfied with their learning experience. Moreover, repeating this investigation is necessary to adopt appropriate policies for the survival of the education system. Therefore, higher education institutions should continuously strive to create a reliable and supportive environment to satisfy their students.

This study calls for further action through seminars and training sessions to introduce innovative teaching techniques and alternative assessment plans for instructors and learners. This study can help educational institutes develop effective techniques for online communication, while helping them manage possible behavioral and emotional difficulties of students during the online learning course. Instructors need to stay involved in promoting collaboration and conversations among students. Our findings also hold implications for institutional e-learning policies aimed at improving learning design models, student support and counseling, and learning analytics.

\section{Limitations}

Although the participants of this study were recruited from several nursing programs across SA, this study has some limitations. First, social desirability may be present in participants' responses due to the nature of a self-report measure. To minimize social desirability, the researchers did not collect any 
identifiers from participants, and the students were informed that their responses would be reported in an aggregate form. Second, the researchers did not assess the differences in the pedagogical style of teaching provided by faculty in different nursing schools. Differences in teaching style, quality of teaching, and quality of instruction practices could be assessed by adopting a between-subjects study design. Due to the differences between the students recruited from each nursing program, it was not feasible to compare their responses based on the type of nursing school.

\section{Conclusion}

This study highlights the satisfaction level regarding assessment methods, teaching methodology, and the integration of students with their peers. It devises strategies for educational institutions to focus on the level of interaction and cooperation of students with each other using participatory teaching methods. Our findings reveal a significant relationship between a sense of community and satisfaction with elearning, which has rarely been documented in prior literature. The rise of e-learning in SA is a major benefit of the COVID-19 pandemic. However, nursing students at advanced levels of schooling might not receive the maximum benefits of e-learning due to the inability to demonstrate their skills in real-world clinical practice. Thus, the combination of traditional teaching-learning method with e-learning may help accomplish these learning objectives.

\section{Declarations}

\section{Ethics approval and consent to participate:}

The Institutional Review Board was obtained from King Saud University (\#KSU-HE-20- 616). Participants signed the consent form prior to filling out the questionnaire. The study was performed in accordance with the Declaration of Helsinki.

Consent for publication: "Not Applicable"

Availability of data and materials:The data that support the findings of this study are available from the corresponding author, [Al], upon reasonable request.

Competing interests: The authors declare that they have no competing interests.

Funding: This study was funded by the Deanship of Scientific Research through the Research Center at the College of Nursing, King Saud University. Please note that King Saud University does not provide funding to the authors until the study has been published. Therefore, no specific grant was provided.

Authors' contributions: Al: Conceptualization, Methodology, Software, Formal Analysis, Writing-original draft. MA: Data curation, Writing-Review and Editing, Validation. MT: Writing- Original draft preparation, Investigation, Project-administration LA: Supervision, Writing- Original draft preparation, Resources. AA: Writing-Review and Editing, Supervision. 
Acknowledgements: The authors are thankful to the Deanship of Scientific Research, College of Nursing Research Center at King Saud University for the support of this research project.

\section{References}

1. Murphy B. How the virus is impacting medical schools. American Medical Association. 2020. Accessed March 1, 2021. https://www.ama-assn.org/delivering-care/public-health/covid-19-howvirus-impacting-medicalschools.

2. Taylor D, Grant J, Hamdy H, Grant L, Marei $H$, Venkatramana M. Transformation to learning from a distance. MedEdPublish. 2020;9(1):76. doi:10.15694/mep.2020.000076.1.

3. Khalil R, Mansour AE, Fadda WA, Almisnid K, Aldamegh M, Al-Nafeesah A, et al. The sudden transition to synchronized online learning during the COVID-19 pandemic in Saudi Arabia: a qualitative study exploring medical students' perspectives. BMC Med Educ. 2020;20:285. doi:10.1186/s12909-020-02208-z.

4. Opeyemi OZ, Adeyemi AA, Olajuwon TD, Nike O, Oloruntosin BSO. Perception of nursing students towards online learning: a case study of Lautech Open and Distance Learning Centre, Ogbomoso, Oyo State, Nigeria. Galore Int J Health Sci Res. 2019;4(4):23-30.

5. Mukhtar K, Javed K, Arooj M, Sethi A. Advantages, limitations and recommendations for online learning during COVID-19 pandemic era. Pak J Med Sci. 2020;36(COVID19-S4):S27-31. doi:10.12669/pjms.36.COVID19-S4.2785.

6. Bdair IA. Nursing students' and faculty members' perspectives about online learning during COVID-19 pandemic: a qualitative study. Teach Learn Nurs. 2021;16:220-6.

7. Bond MA, Lockee BB. Building virtual communities of practice for distance educators. Springer; 2014.

8. Rovai AP. Building sense of community at a distance. Int Rev Res Open Distance Learn. 2002;3(1). doi:10.19173/irrodl.v3i1.79.

9. Glazier RA. Building rapport to improve retention and success in online classes. J Pol Sci Educ. 2016;12(4):437-56. doi:10.1080/15512169.2016.1155994.

10. Luo N, Zhang M, Qi D. Effects of different interactions on students' sense of community in e-learning environment. Comput. Educ. 2017;115:153-60. doi:10.1016/j.compedu.2017.08.006

11. Green T, Hoffmann M, Donovan L, Phuntsog N. Cultural communication characteristics and student connectedness in an online environment: perceptions and preferences of online graduate students. Int J E Learn Distance Educ. 2017;32(2).

12. Trespalacıos J, Perkıns, R. Sense of community, perceived learning, and achievement relationship in an online graduate course. Turk Online J Distance Educ. 2016;17(3):31-49. doi:10.17718/tojde.12984.

13. Shackelford J, Maxwell M. Sense of community in graduate online education: contribution of learner to learner interaction. Int Rev Res Open Distance Learn. 2012;13(4):228-49. 
14. LaBarbera R. The relationship between students' perceived sense of connectedness to the instructor and satisfaction in online courses. Q Rev Distance Educ. 2013;14:209-20.

15. Rockinson-Szapkiw A, Wendt J, Whighting M, Nisbet $D$ The predictive relationship among the community of inquiry framework, perceived learning and online, and graduate students' course grades in online synchronous and asynchronous courses. Int Rev Res Open Distance Learn. 2016;17(3):18-34. doi:10.19173/irrodl.v17i3.2203.

16. Armstrong SN, Early JO, Burcin MM, Bolin K, Holland N, No S. New media tools impact on online, health science students' academic persistence and support: lessons learned from two pilot studies. TechTrends. 2018;62(3):266275. doi:10.1007/s11528-018-0261-1.

17. Abdelmalak M. Web. 2.0 technologies and building online learning communities: students' perspectives. Online Learn. 2015;19(2).

18. Moore RL. Importance of developing community in distance education courses. TechTrends. 2014;58(2):20-4.

19. Top E. Blogging as a social medium in undergraduate courses: sense of community best predictor of perceived learning. Internet High Educ. 2012;15:24-8.

20. Ritter C, Polnick B. Connections: An essential element of online learning communities. Int J Educ Leadersh Preparation. 2008;3(3).

21. Robinson T, Hope W. Teaching in higher education: is there a need for training in pedagogy in graduate degree programs? Res Higher Educ J. 2013:21:1-11.

22. Vilppu H, Södervik I, Postareff L, Murtonen M. The effect of short online pedagogical training on university teachers' interpretations of teaching-learning situations. Instr Sci. 2019; 47(6):679-709. doi:10.1007/s11251-019-09496-z.

23. Fieger P. Measuring student satisfaction from the student outcomes survey. Technical paper. National Centre for Vocational Education Research. 2020. https://eric.ed.gov/?id=ED532394. Accessed January 24, 2021.

24. Alqahtani N, Innab A, Bahari G. Virtual education during COVID-19: exploring factors associated with e-learning satisfaction among Saudi nursing students. Nurse Educ. 2021;46(2):E18-22. doi:10.1097/NNE.0000000000000954

25. Mahyoob M. Online learning effectiveness during the COVID-19 pandemic: a case study of Saudi universities. Int J Inf Commun Technol Educ. 2021;17(4):1-14. doi: 10.4018/IJICTE.20211001.oa7.

26. Aboud Y. Challenges to gifted education in the Covid-19 pandemic about online learning in Saudi Arabia from the perspective of gifted students and parents. Journal of Gifted Education and Creativity. 2021;8(1):11-21.

27. Abbasi MS, Ahmed N, Sajjad B, Alshahrani A, Saeed S, Sarfaraz S, et al. E-Learning perception and satisfaction among health sciences students amid the COVID-19 pandemic. Work. 2020;67(3):54956. doi:10.3233/WOR-203308.

28. Rajabalee YB, Santally MI. Learner satisfaction, engagement and performances in an online module: implications for institutional e-learning policy. Educ Inf Technol. 2020;26:2623-56. 
doi:10.1007/s10639-020-10375-1.

29. Asoodar M, Vaezi S, Izanloo B. Framework to improve e-learner satisfaction and further strengthen elearning implementation. Comput Hum Behav. 2016;63:704-16.

30. Jeong $\mathrm{H}$. Effects of nursing students' practices using smartphone videos on fundamental nursing skills, self-efficacy, and learning satisfaction in South Korea. Eurasia J Math Sci Technol Educ. 2017;13(6):2351-65.

31. Grande RAN, Butcon VER, Indonto MCL, Villacorte LM, Berdida DJE. Quality of life of nursing internship students in Saudi Arabia during the COVID-19 pandemic: a cross-sectional study. Int J Afr Nurs Sci. 2021;14:100301. doi:10.1016/j.ijans.2021.100301. 